University of Nebraska - Lincoln

DigitalCommons@University of Nebraska - Lincoln

USDA National Wildlife Research Center - Staff Publications
U.S. Department of Agriculture: Animal and Plant Health Inspection Service

November 1994

\title{
A COMPARISON OF PLOTLESS DENSITY ESTIMATORS USING MONTE CARLO SIMULATION
}

Richard M. Engeman

Denver Wildlife Research Center, USDA/APHIS, s_r100@yahoo.com

Robert T. Sugihara

Denver Wildlife Research Center, Hawaii Field Station

Larry F. Pank

Alaska Fish \& Wildlife Research Center

William E. Dusenberry

Denver Wildlife Research Center, USDA/APHZS

Follow this and additional works at: https://digitalcommons.unl.edu/icwdm_usdanwrc

Part of the Environmental Sciences Commons

Engeman, Richard M.; Sugihara, Robert T.; Pank, Larry F.; and Dusenberry, William E., "A COMPARISON OF PLOTLESS DENSITY ESTIMATORS USING MONTE CARLO SIMULATION" (1994). USDA National Wildlife Research Center - Staff Publications. 169.

https://digitalcommons.unl.edu/icwdm_usdanwrc/169

This Article is brought to you for free and open access by the U.S. Department of Agriculture: Animal and Plant Health Inspection Service at DigitalCommons@University of Nebraska - Lincoln. It has been accepted for inclusion in USDA National Wildlife Research Center - Staff Publications by an authorized administrator of DigitalCommons@University of Nebraska - Lincoln. 


\title{
A COMPARISON OF PLOTLESS DENSITY ESTIMATORS USING MONTE CARLO SIMULATION ${ }^{1}$
}

\author{
RICHARD M. ENGEMAN \\ Denver Wildlife Research Center, USDA/APHIS, P.O. Box 25266, Denver, Colorado 80225-0266 USA
}

ROBERT T. SUGIHARA

Denver Wildlife Research Center, Hawaii Field Station, USDA/APHIS, P.O. Box 10880, Hilo, Hawaii 96721 USA

LARRY F. PANK

Alaska Fish \& Wildlife Research Center, 1011 East Tudor Road, Anchorage, Alaska 99503 USA

\author{
WiLliam E. DUSENBERRY \\ Denver Wildlife Research Center, USDA/APHIS, P.O. Box 25266, Denver, Colorado 80225-0266 USA
}

\begin{abstract}
We conducted an extensive simulation study to compare the performance of a large group of plotless density estimators (PDEs) to obtain clarification of their relative performance in a diversity of sampling situations. The PDEs studied included well-known ones from the literature plus some extensions and modifications introduced here. The simulations cover 96 combinations of 6 spatial patterns, 4 sample sizes, and 4 population densities. We made comparisons within classes of similar estimators, and we indicate the best-performing PDEs out of the complete set studied.

Over all spatial patterns, the angle-order estimator with measurements to the thirdclosest individual in each quadrant had the lowest relative root-mean-squared error (RRMSE), followed by the same estimation method with measurements to the second closest individual in each quadrant. Also performing well were the variable area transect, the ordered distance estimator using the third closest individual, and an extension of the Kendall-Moran estimator that searches for the second nearest neighbor and pools search areas from all sample points. Opinions and recommendations are given as to which PDEs perform well enough and are practical enough to deserve strong consideration for use in the field.
\end{abstract}

Key words: density estimation; distance methods; plotless methods; spatial pattern.

\section{INTRODUCTION}

A basic problem common in many fields of biology is to estimate the density of stationary objects. The populations of interest most commonly are plant communities, but applications are as diverse as estimating the density of nests for colonial-nesting seabirds or estimating the density of rat damage in sugar cane. The two general sampling approaches available for producing density estimates include the well-known quadrat or plot method and the distance or plotless methods.

An ideal density estimator would be robust for populations from a variety of spatial patterns and densities, and not overly difficult nor expensive in application. Quadrat sampling is robust over spatial patterns (given an appropriate quadrat size), but can be labor intensive, especially when observations are sparse, unevenly distributed, or otherwise difficult to acquire. Cottam (1947) introduced plotless sampling as a method for more easily obtaining density estimates. Many plotless density estimators (PDEs) have since been developed

\footnotetext{
${ }^{1}$ Manuscript received 3 August 1992; revised 22 November 1993; accepted 30 November 1993.
}

to offer efficient approaches for acquiring a sample from which density can be estimated. However, many PDEs were developed assuming a random spatial distribution for the sampled population (e.g., Pollard 1971). While this distributional assumption promotes the development of theory, many, if not most, natural populations tend to occur in clumps or aggregations, such as plant communities and animal damage. At the other extreme, colonial seabird nests can tend towards a more rigid hexagonal or triangular pattern. A variety of estimators have been proposed to offer robust estimation over different spatial patterns (e.g., Morisita 1957, Batcheler 1975, Diggle 1975, Lewis 1975, Patil et al. 1979). Attempts also have been made to modify existing estimators to improve their robustness (e.g., Clayton and Cox 1986) and to calculate the bias of some estimators when certain nonrandom spatial patterns are assumed (e.g., Persson 1971, Diggle 1975). However, little comparative information is available in the literature where a large group of estimators in a variety of circumstances are assessed simultaneously. Our study provides the field investigator with information concerning which estimators yield a reasonably accurate assessment of density, even if the population spatial pattern is unknown or nonrandom. 
In this paper we examine, via a simulation study, the relative statistical properties of many PDEs in a range of circumstances. Our desire is to produce a thorough study of a variety of PDEs to see which, if any, perform well over a range of spatial patterns and population densities, and to determine what sample sizes would be needed for adequate estimation.

\section{Estimation Methods CONSIDERED}

We consider 25 methods for sampling and estimating density. Most are well documented in the literature, and therefore we provide only brief descriptions and references. We also consider some modifications or extensions to existing estimators. We attempt to group estimators into subsections based on the use of similar measurement methods, but even so, we develop an abbreviated labelling scheme to facilitate our tables and discussions. The formulae and references relating to the estimators used in this study are summarized in Table 1.

Before we describe the estimators that are included in the study, we mention some distance sampling methods that are excluded. A general categorization of these methods might be as "line-of-sight" methods, i.e., those methods needing a clear line of sight to the objects of interest to have a practical implementation in the field. Among these methods are line transect sampling (Burnham et al. 1980), variable circular plot sampling (Buckland 1987), and that described by Delince (1986). The methods we study are applicable when an area must be thoroughly searched to find the objects of interest as well as when they are more readily visible to the investigator. The line-of-sight methods tend to become overly arduous or become equivalent to other methods when an area is completely searched. Also, for these methods, the simulation programming would become substantially more difficult and additional considerations, such as different sighting functions, would need to be included in the simulation design.

\section{"Basic" distance (BD) estimators}

The "basic" distance methods involve two types of measurements-from randomly placed sample points to the closest individual in the population (point-toindividual), or from individuals (usually the closest individual) to their nearest neighbor (individual-to-individual). An additional measurement is sometimes made from the nearest neighbor to its nearest neighbor, which we refer to as the second nearest neighbor. We use the following notation for the five density estimators in this section (Table 1) and for descriptions elsewhere in the paper: $N=$ sample size (number of random sample points used to gather distance measurements), $R_{(1) i}=$ distance from the $i^{\text {th }}$ sample point to the closest individual, $H_{(1) i}=$ distance from the $i^{\text {th }}$ closest individual to its nearest neighbor, $H_{(2) i}=$ distance from the nearest neighbor at the $i^{\text {th }}$ random point to the second nearest neighbor.
BDCI is the estimate of density based on the distances to the closest individual (CI) (Cottam et al. 1953, Cottam and Curtis 1956). The formula (Table 1) incorporates the $R_{(1)}$ distances in a manner that approximates the use of search areas (e.g., Kendall and Moran 1963, Pollard 1971). BDNN similarly uses the nearest neighbor (NN) measurements (Table 1) to produce a density estimate (Cottam and Curtis 1956). BD2N uses the same formula to estimate density with the second nearest neighbor measurements. The potential lack of robustness for the preceding distance estimators when the spatial pattern deviates from randomness is well recognized (e.g., Cottam et al. 1957, Pollard 1971, Clayton and Cox 1986). Diggle (1975) discusses the use of a compound estimator that is simply a mean of the first two, which we label BDAV2. We also consider a compound estimator, BDAV3, that is the mean of the BDCI, BDNN, and BD2N (Table 1).

\section{"Batcheler-Bell" (BB) estimators}

Estimators based on samples where the search radii are restricted and that incorporate corrections for bias arising from nonrandomness were described by Batcheler and Bell (1970) and advanced in subsequent papers (e.g., Batcheler 1971, 1975). An estimate of density is made by using the measurements on the distance to the closest individual, and this estimate is corrected for bias using the distance to the nearest neighbor and the second nearest neighbor. The additional notation needed in Table 1 for presenting the Batcheler-Bell estimates includes: $R_{\max }=$ maximum search radius, $p$ $=$ number of untruncated measurements to the closest individual (number of measurements $<$ restriction on search distance). BBCI is the Batcheler-Bell estimator uncorrected for nonrandomness (Batcheler and Bell 1970). BBNR uses the $H_{(1)}$ and $H_{(2)}$ measurements to correct $\mathrm{BBCI}$ for bias due to nonrandomness. Application of the correction factors involves a series of calculations depending on which of several cases are involved. See Batcheler and Bell (1970) for a description of the cases and how the correction is to be applied for each.

\section{Nonparametric (NP) estimators}

In an effort to avoid assumptions about the spatial pattern of the sampled population, Patil et al. (1979) developed a nonparametric estimator that uses search areas to closest individuals, $A_{i}=\pi R^{2}{ }_{(1) i}$. Using the theory on order statistics, one of the $N$ search areas is selected to be used in the density estimate. If we let $A_{(i)}$ represent the $i^{\text {th }}$ smallest-order statistic, then the general form of their nonparametric estimator appears as $k(N) / N A_{([k(N)])}$, where [] denotes the greatest integer function and $k(N)$ is an increasing sequence satisfying certain regularity conditions defined in Patil et al. (1979). In their original paper, they suggested using $k(N)=N^{1 / 2}$ (Patil et al. 1979), but in a following paper they proposed that $k(N)=N^{2 / 3}$ is optimal in terms of 
TABLE 1. Summary of the density estimators used in the simulations, their formulae, and the primary references.

\begin{tabular}{ccc}
\hline \hline Description* & Formula ${ }^{*}$ & References \\
\hline
\end{tabular}

Basic Distance (BD) estimators

1. Closest individual (CI)

2. Nearest neighbor (NN)

3. Second nearest neighbor $(2 \mathrm{~N})$

4. Compound

5. Another compound

Batcheler-Bell (BB) estimators

6. Closest individual (CI)

7. Nonrandomness (NR) corrected

Non-parametric (NP) estimators

8. Original bias reduced (i.e., general form [GF])

9. Interpolated original general form (IG)

10. Optimal form (OF)

11. Interpolated optimal form (IO)

Kendall-Moran (KM) estimators

12. $\mathrm{CI}$ and $\mathrm{NN}$ search areas pooled $(\mathrm{P})$

13. $\mathrm{CI}, \mathrm{NN}, 2 \mathrm{~N}$ search areas pooled (i.e., pooled with search area to $2 \mathrm{~N}[2 \mathrm{P}])$

T-Square (TS) estimators

14. Basic $\mathrm{T}^{2}$ estimator (BA)

15. Reduced bias (RB) in aggregated populations

16. Robust (Byth [B])

Ordered Distance (OD) estimators

17. Closest individual

18. Second closest individual (2C)

19. Third closest individual (3C)

Angle-Order (AO) estimators

20. Point-centered-quarter (i.e., 1 observation per quadrant [1Q])

21. Second closest individual in each quadrant (2Q)

22. Third closest individual in each quadrant (3Q)

23. Third closest individual in each quadrant (3)

Variable Area Transect (VAT)

24. Variable area transect

Quadrat (QUAD)

25. Quadrat
$\mathrm{BDCI}=1 /\left(4\left[\Sigma R_{(1) i} / N\right]^{2}\right)$

$\mathrm{BDNN}=1 /\left(2.778\left[\Sigma H_{(1) i} / N\right]^{2}\right)$

$\mathrm{BD} 2 \mathrm{~N}=1 /\left(2.778\left[\Sigma H_{(2) i} / N\right]^{2}\right)$

$\mathrm{BDAV} 2=(\mathrm{BDCI}+\mathrm{BDNN}) / 2$

$\mathrm{BDAV} 3=(\mathrm{BDCI}+\mathrm{BDNN}+\mathrm{BD} 2 \mathrm{~N}) / 3$

$\mathrm{BBCI}=p / \pi\left[\Sigma R_{(1) i}^{2}+(N-p) R^{2}\right]$

BBNR (see reference)

$\mathrm{NPGF}=\left(N^{1 / 2}-1\right) / N A_{\left(\left[N^{1 / 3}\right]\right)}$

$\mathrm{NPIG}=\left(N^{1 / 2}-1\right) / N A^{*}{ }_{\left(N^{1 / 2}\right)}$

$\mathrm{NPOF}=\left(N^{2 / 3}-1\right) / N A_{\left(\left[N^{2 / 3}\right)\right.}$

$\mathrm{NPIO}=\left(N^{2 / 3}-1\right) / N A^{*}{ }_{\left(N^{2 /}\right)}$

$\mathrm{KMP}=\left\{\left[\Sigma\left(p_{i}+n_{i}\right)\right]-1\right\} / \Sigma B_{i}$

$\mathrm{KM} 2 \mathrm{P}=\left\{\left[\Sigma\left(p_{i}+n_{i}+m_{i}\right)\right]-1\right\} / \Sigma C_{i}$

$\mathrm{TSBA}=2 N /\left[\pi \Sigma \mathrm{R}_{(1) i}{ }^{2}+0.5 \pi \Sigma T_{i}^{2}\right]$

$\mathrm{TSRB}=N / \pi\left[\left(\Sigma \mathrm{R}_{(1) i}{ }^{2}\right)\left(0.5 \Sigma T_{i}^{2}\right)\right]^{1 / 2}$

$\mathrm{TSB}=N^{2} /\left[\left(2 \Sigma \mathrm{R}_{(1) i}\right)(\sqrt{2})\left(\Sigma T_{i}\right)\right]$

ODCI $=(N-1) / \pi \Sigma\left(R_{(1) i}\right)^{2}$

$\mathrm{OD} 2 \mathrm{C}=(2 N-1) / \pi \Sigma\left(R_{(2) i}\right)^{2}$

OD3C $=(3 N-1) / \pi \Sigma\left(R_{(3) i}\right)^{2}$

$\mathrm{AO} 1 \mathrm{Q}=12 N / \pi \Sigma 1 / R_{(1) i j}{ }^{2}$

$\mathrm{AO} 2 \mathrm{Q}=28 N / \pi \Sigma 1 / R_{(2) i j}{ }^{2}$

$\mathrm{AO} 3 \mathrm{Q}=44 N / \pi \Sigma 1 / R_{(3) i j}{ }^{2}$

$\mathrm{AO} 3=[2 / \pi N] \Sigma \Sigma\left(1 / R_{(3) i j}\right)$

$\left.\mathrm{VAT}=(3 N-1) / w \Sigma l_{i}\right)$

$\mathrm{QUAD}=\Sigma q_{i} /\left(l_{i} w_{i} N\right)$
Parker 1979

Cottam et al. 1953, Cottam and Curtis 1956, Kendall and Moran 1963, Pollard 1971

Cottam and Curtis 1956

Cottam and Curtis 1956

Diggle 1975

This paper

Batcheler and Bell 1970

Batcheler and Bell 1970

Patil et al. 1979

This paper

Patil et al. 1982

This paper

Kendall and Moran 1963,

James 1971

Kendall and Moran 1963

Diggle 1975

Diggle 1975

Byth 1982

Morisita 1957, Pollard 1971

Morisita 1957, Pollard 1971

Morisita 1957, Pollard 1971

Stearns 1949, Cottam et al. 1953, Cottam and Curtis 1956, Morisita 1957, Pollard 1971

Morisita 1957, Pollard 1971

Morisita 1957, Pollard 1971

Morisita 1971

None

* AO = angle-order estimator, AV2 = average of two methods, AV3 = average of three methods, $\mathrm{B}=\mathrm{Byth}(1982), \mathrm{BA}=$ basic, $\mathrm{BB}=$ Batcheler-Bell estimator, $\mathrm{BD}=$ basic distance estimator, $\mathrm{CI}=$ closest individual, $\mathrm{GF}=$ general form, $\mathrm{IG}=$ interpolated general form, $\mathrm{IO}=$ interpolated optimal form, $\mathrm{KM}=$ Kendall-Moran estimator, $\mathrm{NN}=$ nearest neighbor, $\mathrm{NP}=$ nonparametric estimator, $\mathrm{NR}=$ not randomness corrected, $\mathrm{OD}=$ ordered-distance estimator, OF $=$ optimal form, QUAD $=$ quadrat estimator, $\mathrm{RB}=$ reduced bias, $\mathrm{TS}=\mathrm{T}$-squared $\left(\mathrm{T}^{2}\right)$ estimator, $\mathrm{VAT}=$ variable area transect estimator, $2 \mathrm{C}=$ second-closest individual, $3 \mathrm{C}=3 \mathrm{rd} \mathrm{CI}, 2 \mathrm{~N}=2 \mathrm{nd} \mathrm{NN}, 3 \mathrm{~N}=3 \mathrm{rd} \mathrm{NN}, 2 \mathrm{P}=$ pooled with search area to $2 \mathrm{nd} \mathrm{NN}, 1 \mathrm{Q}=1$ observation per quadrat, $2 \mathrm{Q}=2$ observations/quadrat, $3 \mathrm{Q}=3$ observations/quadrat.

$\dagger A_{(i)}=$ the $i^{\text {th }}$ smallest-order statistic for search areas; $A^{*}{ }_{(i)}=$ the interpolated value between the $i^{\text {th }}$ - and the $(i+1)^{\text {st }}$-order statistic for search areas; $B_{i}=$ the total search area at the $i^{\text {th }}$ sample point for the CI and its NN combined; $C_{i}=$ the total search area at the $i^{\text {th }}$ sample point for the CI, its NN, and the second NN combined; $H_{0) i}=$ the distance from the $i^{\text {th }} \mathrm{CI}$ to its $\mathrm{NN} ; H_{(2) i}=$ the distance from the $\mathrm{NN}$ at the $i^{\text {th }}$ random point to the second $\mathrm{NN} ; l_{i}=$ the length searched from the random point to the $g^{\text {th }}$ individual; $N=$ the sample size (number of random sample points used to gather distance measurements; $p$ $=$ the number of untruncated measurements to the CI; [ ] denotes the greatest integer function; $p_{i}, n_{i}$, and $m_{i}=$ the number of CIs, NNs, and 2nd NNs, respectively; $R_{(1) i}=$ the distance from the $i^{\text {th }}$ sample point to the CI; $R_{(g) i j}=$ the distance from the $i^{\text {th }}$ sample point to the $g^{\text {th }} \mathrm{CI}$ in the $j^{\text {th }}$ sector; $T_{i}=$ the distance from the CI to its NN on the far side of the half-plane defined by the line through the CI that is perpendicular to the line from the random point to that CI; $w=$ the width of the strip transect (in VAT); $w_{i}=$ the width of the quadrat estimator (in QUAD). 
precision and that a biased reduced form of the density estimator should be used (Patil et al. 1982): $(k(N)-$ 1) $/ N A_{([k(N)])}$.

Here we use interpolation between the ordered search areas that bracket the sequence value, instead of the greatest integer function to select a specific search area from which the density estimate is calculated. That is, rather than select the $[k(N)]^{\text {th }}$ order statistic from among the ordered $A_{(i)}$, the density estimate is calculated using linear interpolation between $A_{(i)}$ and $A_{(i+1)}$, where $i \leq$ $k(N) \leq i+1$. We denote this interpolated value as $A^{*}$. A comparison of the two sequences recommended for selecting among the search areas and the effect of interpolation on estimation is included as part of the present study.

NPGF uses the Patil et al. (1979) original suggestion of $k(N)=N^{1 / 2}$, but applies it in the bias-reduced form (Patil et al. 1982). NPIG is the interpolated version of NPGF. NPOF is the optimal and biased-reduced form of the nonparametric estimator recommended in Patil et al. (1982), where $k(N)=N^{2 / 3}$. NPIO is the interpolated version of NPOF. The specific formulae used for these estimators are given in Table 1.

\section{"Kendall-Moran" (KM) estimators}

Kendall and Moran (1963) presented estimation methods that incorporated the total area searched for the closest individual and its nearest neighbor. The area searched is not $\pi R^{2}{ }_{(1)}+\pi H^{2}{ }_{(1)}$, but rather is the sum of the areas minus their intersection (see also James 1971). We also consider an estimator where the search area to the second nearest neighbor is incorporated into the estimates. The calculations for this estimator require a much more complex algorithm to consider all possible geometrical configurations for the possible intersections of the three search areas. This algorithm was developed by one of the authors (L. F. Pank) for assessing rat damage levels in Hawaiian sugar cane. We use the following notation to describe the KM estimators. $B_{i}=$ total search area at the $i^{\text {th }}$ sample point for the closest individual and its nearest neighbor combined. $C_{i}=$ total search area at the $i^{\text {th }}$ sample point for the closest individual, its nearest neighbor, and the second nearest neighbor combined. The number of closest individuals, nearest neighbors, and second nearest neighbors located are denoted as $p_{i}, n_{i}$, and $m_{i}$, respectively. The KMP estimator pools the closest individual and nearest neighbor search areas from all sample points to calculate a density estimate. Similar to KMP, the KM2P estimator pools across all sample points the search areas for the closest individual, its nearest neighbor, and the second nearest neighbor.

\section{$T$-square (TS) estimators}

T-square $\left(\mathrm{T}^{2}\right)$ estimators evolved as methods to remove bias due to nonrandomness associated with the nearest neighbor distance measurement (Besag and Gleaves 1973). The nearest-neighbor distance in
$\mathrm{T}$-square sampling, $\mathrm{T}_{i}$, is the distance from the closest individual to its nearest neighbor on the far side of the half-plane defined by the line through the closest individual that is perpendicular to the line from the random point to that closest individual. We consider the basic T-square estimator, TSBA (Diggle 1975); a reduced biased form, TSRB, presented in Diggle (1975); and TSB, the T-square estimator Byth (1982) found to be most robust ( $\mathrm{E}^{*}$ in her notation). The formulae for these estimators are given in Table 1.

\section{Ordered distance $(O D)$ estimators}

Morisita (1957) described and developed the theory for several estimation methods. Included among these is the ordered distance method, the theory for which was further developed by Pollard (1971). The method involves measuring the distance from the random sampling point to the $g^{\text {th }}$ closest individual (hence the ordering). We define the distance to the $g^{\text {th }}$ closest individual at the $i^{\text {th }}$ sample point as $R_{(g) i}$. The general formula for the ordered distance estimator is $(g N-$ $1) / \pi \Sigma\left(R_{(g) i}\right)^{2}$.

Pollard (1971) demonstrated that, for the random spatial pattern, as $g$ increases, the variance of the density estimate decreases. However, he also indicated that using $g>3$ may be impractical in the field. We therefore consider $g=1,2$, and 3 (ODCI, OD2C, and OD3C, respectively) in our simulation study. The specific formulae for these estimators are given in Table 1.

\section{Angle-order (AO) estimators}

The point-centered-quarter method is an old method dating back to the 19th century when it was used by federal land surveyors on government lands (Stearns 1949). As adapted for ecological sampling, the area around the random point is divided into four quarters and the distance to the closest individual in each quarter is measured (e.g., Cottam and Curtis 1956). Cottam et al. (1953) presented an empirical development of the method and Morisita (1954) provided theoretical development. Morisita (1957) later derived the angleorder sampling method where the area around the random sample point is divided into $k$ equiangular sectors and the distance to the $g^{\text {th }}$ closest individual in each sector is measured. Morisita (1957) considered $k=4$ and $g=3$ as practical. The angle-order method presumes to overcome the problem of nonrandomly distributed individuals by assuming that the area can be divided into fractions where the individuals are arranged randomly. When $k=4$ the sampling is frequently called point-centered-quarter sampling and traditionally involves $g=1$ (e.g., Pollard 1971). We consider four estimators in this section and we define $k$ as the number of equiangular sectors about the random sample point (we use $k=4$ for each estimator), $g$ as the number of individuals to be located in each sector of the area around the random sampling point (each estimator uses a value of $g \leq 3$ to remain in the 
realm of what Morisita (1957) considered practical for field sampling) and $R_{(g) i j}$ as the distance from the $i^{\text {th }}$ sample point to the $g^{\text {th }}$ closest individual in the $j^{\text {th }}$ sector. The general form of the estimator is $[N k(g k-$ $1) / \pi] \Sigma 1 / R_{(g) i j}^{2}$. Estimators AO1Q, AO2Q, and AO3Q in Table 1 use $g=1,2$, and 3, respectively. A different formula (Morisita 1957), based on the distance to the third closest individual in each sector $(g=3)$, provides the final estimator that we consider in this section. Its general form is $[(g-1) / \pi N] \Sigma \Sigma\left(1 / R_{(g) i j}\right)$, and $\mathrm{AO} 3$ in Table 1 uses $g=3$.

\section{Variable area transect (VAT) estimator}

The final PDE method we include is the variable area transect estimator by Parker (1979). It can be considered as a combination of distance and quadrat methods, because a fixed-width (strip) transect is searched from a random point until the $g^{\text {th }}$ individual is encountered in the strip. For notation we define $g$ as the number of individuals searched for (beginning at each random point), $w$ as the width of the strip transect, and $l_{i}$ as the length searched from the random point to the $g^{\text {th }}$ individual. The general formula for the VAT estimator is $(N g-1) /\left(w \Sigma l_{i}\right)$.

\section{Quadrat estimator}

We include quadrat estimation of density for the purposes of general comparison. We do not attempt to optimize quadrat properties, but use the same standard size (length and width) throughout. If we let $w_{i}=$ width of quadrat and $l_{i}=$ length of quadrat, then the general formula for the estimate is $\Sigma q_{i} /\left(l_{i} w_{i} N\right)$.

\section{Simulation Study Design}

The behaviors of the 25 sampling and estimation methods were evaluated through a Monte Carlo simulation study. A simulation program was written in Microsoft FORTRAN 77 (Version 5.0, MS-DOS operating system), each run of which was designated by a specific combination of population spatial pattern, population density, and sample size (of random sampling points). We examined 96 combinations encompassing 6 spatial patterns, 4 densities, and 4 sample sizes.

The uniform random-number generator used for placing population individuals and locating sampling points was the UNIF routine (Bratley et al. 1983) and, where required, the VNORM routine (Bratley et al. 1983) was used to convert the uniform random numbers to normal random numbers. UNIF has been extensively tested for uniformity, independence, and nonperiodicity of the numbers generated and VNORM tested for accuracy (Brody and Morais 1987).

The density used in a particular run of the program was specified by inputting the size of a rectangular area (the length of each dimension) and the number of individuals to reside in that area. We examined target population densities of $2,5,10$, and 20 individuals per unit area. The area used for each density was large enough to ensure that the target population was several orders of magnitude larger than the number of sampling points.

We identify the six spatial patterns for the populations simulated in this study as random, regular, triangular, aggregate-50, aggregate-15, and double clumped. The random pattern (also called Poisson in recognition of the fact that the points are distributed as a two-dimensional Poisson process) was simulated by generating the appropriate number of random coordinates in the designated area. The regular spatial pattern was generated by dividing the area into a grid of rectangles, the same number as individuals in the population. The population members were then situated by randomly locating one individual in each rectangle. The triangular patterns (sometimes referred to as a hexagonal pattern) were generated so that the population members were located at the vertices of a lattice of equilateral triangles. For the two aggregate patterns, the centers of a user-specified number of clumps were randomly located in the designated area. In addition to the clump center point, a user-specified number of "offspring" for the clumps were located within a userspecified radius of the center (parent) point. These offspring were located within the clump about the parent point using coordinates randomly generated from the standard bivariate normal distribution. This tends to concentrate the members of the clump near to the center point. The aggregate patterns approximate many of the naturally occurring biological population patterns. We only considered clumps of five individuals (the center point or "parent" and four "offspring"). The aggregate-50 pattern was moderately clumped, with the offspring located within clump radii of 50 distance units. The aggregate- 15 pattern was severely clumped, with the offspring located within clump radii of 15 distance units. The pattern we label as double clumped is a second-order aggregation that was generated in a similar fashion to the aggregate- 15 pattern. The difference is that for the double-clumped pattern the individuals in the clumps of the aggregate- 15 pattern are used for center points (parents) for subclumps of two individuals. The two individuals of the subclumps include the parent plus one other point (offspring) randomly generated from the standard bivariate normal distribution. The radius for the subclump is restricted to be one half that for the clump ( 7.5 units). This spatial pattern approximates some of the field patterns that we have observed for rodent burrows and animal damage locations. It also provides one of the severest tests of the estimation methods.

Each plotless density estimator (PDE) assessed required randomly located sampling points to initiate the sampling procedures. The sample sizes considered in this study refer to the number of random sampling points placed in the population. Sample sizes that we examined were $5,10,20$, and 50 random points. In 
TABLE 2. Mean RRMSE (relative root-mean-squared error) results for each estimator in each spatial pattern at each sample size $(5,10,20,50)$. Estimator notation defined in Table 1.

\begin{tabular}{|c|c|c|c|c|c|c|c|c|c|c|c|c|c|c|c|}
\hline \multirow[b]{3}{*}{ Estimator } & \multicolumn{15}{|c|}{ Pattern } \\
\hline & \multicolumn{5}{|c|}{ Random samples } & \multicolumn{5}{|c|}{ Regular samples } & \multicolumn{5}{|c|}{ Triangular } \\
\hline & 5 & 10 & 20 & 50 & Mean & 5 & 10 & 20 & 50 & Mean & 5 & 10 & 20 & 50 & Mean \\
\hline \multicolumn{16}{|l|}{ Basic distance } \\
\hline $\begin{array}{l}\text { 1. BDCI } \\
\text { 2. BDNN } \\
\text { 3. BD2N } \\
\text { 4. BDAV2 } \\
\text { 5. BDAV3 }\end{array}$ & $\begin{array}{l}0.78 \\
0.77 \\
0.72 \\
0.60 \\
0.50\end{array}$ & $\begin{array}{l}0.42 \\
0.45 \\
0.40 \\
0.34 \\
0.28\end{array}$ & $\begin{array}{l}0.27 \\
0.28 \\
0.25 \\
0.21 \\
0.17\end{array}$ & $\begin{array}{l}0.16 \\
0.18 \\
0.16 \\
0.13 \\
0.11\end{array}$ & $\begin{array}{l}0.41 \\
0.42 \\
0.38 \\
0.32 \\
0.27\end{array}$ & $\begin{array}{l}0.91 \\
0.36 \\
0.38 \\
0.48 \\
0.31\end{array}$ & $\begin{array}{l}0.57 \\
0.24 \\
0.34 \\
0.28 \\
0.18\end{array}$ & $\begin{array}{l}0.43 \\
0.19 \\
0.33 \\
0.19 \\
0.13\end{array}$ & $\begin{array}{l}0.34 \\
0.17 \\
0.33 \\
0.13 \\
0.09\end{array}$ & $\begin{array}{l}0.56 \\
0.24 \\
0.35 \\
0.27 \\
0.18\end{array}$ & $\begin{array}{l}1.13 \\
0.66 \\
0.68 \\
0.42 \\
0.33\end{array}$ & $\begin{array}{l}0.83 \\
0.66 \\
0.68 \\
0.26 \\
0.29\end{array}$ & $\begin{array}{l}0.69 \\
0.66 \\
0.68 \\
0.18 \\
0.27\end{array}$ & $\begin{array}{l}0.61 \\
0.66 \\
0.68 \\
0.12 \\
0.27\end{array}$ & $\begin{array}{l}0.81 \\
0.66 \\
0.68 \\
0.25 \\
0.29\end{array}$ \\
\hline \multicolumn{16}{|l|}{ Batcheler-Bell } \\
\hline $\begin{array}{l}\text { 6. } \mathrm{BBCI} \\
\text { 7. } \mathrm{BBNR}\end{array}$ & $\begin{array}{l}0.80 \\
0.60\end{array}$ & $\begin{array}{l}0.42 \\
0.38\end{array}$ & $\begin{array}{l}0.26 \\
0.26\end{array}$ & $\begin{array}{l}0.15 \\
0.16\end{array}$ & $\begin{array}{l}0.41 \\
0.35\end{array}$ & $\begin{array}{l}0.98 \\
0.55\end{array}$ & $\begin{array}{l}0.62 \\
0.33\end{array}$ & $\begin{array}{l}0.49 \\
0.23\end{array}$ & $\begin{array}{l}0.40 \\
0.14\end{array}$ & $\begin{array}{l}0.62 \\
0.31\end{array}$ & $\begin{array}{l}1.28 \\
0.49\end{array}$ & $\begin{array}{l}0.97 \\
0.30\end{array}$ & $\begin{array}{l}0.80 \\
0.21\end{array}$ & $\begin{array}{l}0.68 \\
0.12\end{array}$ & $\begin{array}{l}0.93 \\
0.28\end{array}$ \\
\hline \multicolumn{16}{|l|}{ Nonparametric } \\
\hline $\begin{array}{l}\text { 8. NPGF } \\
\text { 9. NPIG } \\
\text { 10. NPOF } \\
\text { 11. NPIO }\end{array}$ & $\begin{array}{l}2.13 \\
0.81 \\
3.41 \\
0.82\end{array}$ & $\begin{array}{l}1.13 \\
0.69 \\
0.71 \\
0.50\end{array}$ & $\begin{array}{l}0.79 \\
0.55 \\
0.43 \\
0.39\end{array}$ & $\begin{array}{l}0.44 \\
0.43 \\
0.29 \\
0.29\end{array}$ & $\begin{array}{l}1.13 \\
0.62 \\
1.21 \\
0.50\end{array}$ & $\begin{array}{l}2.37 \\
0.84 \\
3.78 \\
0.82\end{array}$ & $\begin{array}{l}0.86 \\
0.63 \\
0.69 \\
0.45\end{array}$ & $\begin{array}{l}0.78 \\
0.52 \\
0.40 \\
0.36\end{array}$ & $\begin{array}{l}0.42 \\
0.41 \\
0.28 \\
0.26\end{array}$ & $\begin{array}{l}1.11 \\
0.60 \\
1.29 \\
0.47\end{array}$ & $\begin{array}{l}2.28 \\
0.74 \\
3.66 \\
0.70\end{array}$ & $\begin{array}{l}0.90 \\
0.65 \\
0.74 \\
0.45\end{array}$ & $\begin{array}{l}0.87 \\
0.56 \\
0.42 \\
0.35\end{array}$ & $\begin{array}{l}0.42 \\
0.41 \\
0.28 \\
0.25\end{array}$ & $\begin{array}{l}1.12 \\
0.59 \\
1.28 \\
0.44\end{array}$ \\
\hline \multicolumn{16}{|l|}{ Kendall-Moran } \\
\hline $\begin{array}{l}\text { 12. } \mathrm{KMP} \\
\text { 13. } \mathrm{KM} 2 \mathrm{P}\end{array}$ & $\begin{array}{l}0.39 \\
0.32\end{array}$ & $\begin{array}{l}0.26 \\
0.22\end{array}$ & $\begin{array}{l}0.18 \\
0.15\end{array}$ & $\begin{array}{l}0.11 \\
0.10\end{array}$ & $\begin{array}{l}0.24 \\
0.20\end{array}$ & $\begin{array}{l}0.26 \\
0.18\end{array}$ & $\begin{array}{l}0.19 \\
0.13\end{array}$ & $\begin{array}{l}0.15 \\
0.09\end{array}$ & $\begin{array}{l}0.11 \\
0.06\end{array}$ & $\begin{array}{l}0.18 \\
0.12\end{array}$ & $\begin{array}{l}0.49 \\
0.51\end{array}$ & $\begin{array}{l}0.44 \\
0.49\end{array}$ & $\begin{array}{l}0.44 \\
0.48\end{array}$ & $\begin{array}{l}0.44 \\
0.48\end{array}$ & $\begin{array}{l}0.46 \\
0.49\end{array}$ \\
\hline \multicolumn{16}{|l|}{ T-Square } \\
\hline $\begin{array}{l}\text { 14. TSBA } \\
\text { 15. TSRB } \\
\text { 16. TSB }\end{array}$ & $\begin{array}{l}0.64 \\
0.72 \\
0.67\end{array}$ & $\begin{array}{l}0.44 \\
0.48 \\
0.45\end{array}$ & $\begin{array}{l}0.33 \\
0.36 \\
0.34\end{array}$ & $\begin{array}{l}0.26 \\
0.28 \\
0.26\end{array}$ & $\begin{array}{l}0.42 \\
0.46 \\
0.43\end{array}$ & $\begin{array}{l}0.57 \\
0.63 \\
0.50\end{array}$ & $\begin{array}{l}0.46 \\
0.48 \\
0.36\end{array}$ & $\begin{array}{l}0.40 \\
0.41 \\
0.29\end{array}$ & $\begin{array}{l}0.37 \\
0.37 \\
0.25\end{array}$ & $\begin{array}{l}0.45 \\
0.47 \\
0.35\end{array}$ & $\begin{array}{l}0.18 \\
0.22 \\
0.24\end{array}$ & $\begin{array}{l}0.18 \\
0.16 \\
0.20\end{array}$ & $\begin{array}{l}0.17 \\
0.12 \\
0.19\end{array}$ & $\begin{array}{l}0.17 \\
0.09 \\
0.18\end{array}$ & $\begin{array}{l}0.18 \\
0.15 \\
0.20\end{array}$ \\
\hline \multicolumn{16}{|c|}{ Ordered distance } \\
\hline $\begin{array}{l}\text { 17. ODCI } \\
\text { 18. OD2C } \\
\text { 19. OD3C }\end{array}$ & $\begin{array}{l}0.58 \\
0.36 \\
0.28\end{array}$ & $\begin{array}{l}0.37 \\
0.25 \\
0.20\end{array}$ & $\begin{array}{l}0.24 \\
0.17 \\
0.14\end{array}$ & $\begin{array}{l}0.15 \\
0.11 \\
0.09\end{array}$ & $\begin{array}{l}0.34 \\
0.22 \\
0.18\end{array}$ & $\begin{array}{l}0.68 \\
0.32 \\
0.21\end{array}$ & $\begin{array}{l}0.54 \\
0.27 \\
0.18\end{array}$ & $\begin{array}{l}0.48 \\
0.25 \\
0.17\end{array}$ & $\begin{array}{l}0.45 \\
0.24 \\
0.16\end{array}$ & $\begin{array}{l}0.54 \\
0.27 \\
0.18\end{array}$ & $\begin{array}{l}0.96 \\
0.20 \\
0.28\end{array}$ & $\begin{array}{l}0.98 \\
0.20 \\
0.30\end{array}$ & $\begin{array}{l}1.00 \\
0.20 \\
0.32\end{array}$ & $\begin{array}{l}1.01 \\
0.20 \\
0.32\end{array}$ & $\begin{array}{l}0.99 \\
0.20 \\
0.31\end{array}$ \\
\hline \multicolumn{16}{|l|}{ Angle-Order } \\
\hline $\begin{array}{l}\text { 20. } \mathrm{AO} 1 \mathrm{Q} \\
\text { 21. } \mathrm{AO} 2 \mathrm{Q} \\
\text { 22. } \mathrm{AO} 3 \mathrm{Q} \\
\text { 23. } \mathrm{AO} 3\end{array}$ & $\begin{array}{l}0.32 \\
0.19 \\
0.15 \\
0.22\end{array}$ & $\begin{array}{l}0.23 \\
0.13 \\
0.10 \\
0.16\end{array}$ & $\begin{array}{l}0.16 \\
0.10 \\
0.08 \\
0.12\end{array}$ & $\begin{array}{l}0.11 \\
0.06 \\
0.05 \\
0.08\end{array}$ & $\begin{array}{l}0.20 \\
0.12 \\
0.10 \\
0.14\end{array}$ & $\begin{array}{l}0.26 \\
0.13 \\
0.09 \\
0.13\end{array}$ & $\begin{array}{l}0.22 \\
0.11 \\
0.08 \\
0.12\end{array}$ & $\begin{array}{l}0.19 \\
0.10 \\
0.07 \\
0.11\end{array}$ & $\begin{array}{l}0.18 \\
0.10 \\
0.07 \\
0.11\end{array}$ & $\begin{array}{l}0.21 \\
0.11 \\
0.08 \\
0.12\end{array}$ & $\begin{array}{l}0.47 \\
0.09 \\
0.13 \\
0.10\end{array}$ & $\begin{array}{l}0.47 \\
0.09 \\
0.13 \\
0.10\end{array}$ & $\begin{array}{l}0.47 \\
0.09 \\
0.13 \\
0.10\end{array}$ & $\begin{array}{l}0.47 \\
0.09 \\
0.13 \\
0.10\end{array}$ & $\begin{array}{l}0.47 \\
0.09 \\
0.13 \\
0.10\end{array}$ \\
\hline 24. VAT & 0.28 & 0.19 & 0.14 & 0.09 & 0.18 & 0.23 & 0.20 & 0.17 & 0.16 & 0.19 & 0.43 & 0.38 & 0.35 & 0.34 & 0.37 \\
\hline 25. QUAD & 0.19 & 0.13 & 0.09 & 0.06 & 0.12 & 0.10 & 0.07 & 0.05 & 0.04 & 0.07 & 0.08 & 0.06 & 0.04 & 0.03 & 0.05 \\
\hline
\end{tabular}

this study we concentrated on only the properties of the estimators as originally defined, without considering truncation formulae for restricted search areas. We also avoided edge effects by rejecting sample points where the search area encountered an edge prior to finding an object of interest. The effects of both of these considerations merit further attention in a separate study.

There was one run of the simulation program for each spatial pattern $\times$ density $\times$ sample size combination. At each replication of each run of the simulation program, a new population was generated and a new set of random sampling points applied. Each simulation run was comprised of 5000 such replications, which is much larger than most PDE simulation studies that have appeared in the literature to date. The observed statistics accumulated over the 5000 replications for each estimator included the mean density estimate, variance, relative bias, mean squared error (MSE), and the relative root-mean-squared error (RRMSE). We used the RRMSE as the primary cri- terion for comparing the performance of the estimators (see, for example, Patil et al. 1979, Engeman and Bromaghin 1990), because it encompasses variance and bias, and it is unitless. RRMSE was calculated as

$$
\operatorname{RRMSE}=\left\{\left[\Sigma\left(\left(D_{e}-D\right)^{2} / D^{2}\right)\right] / I\right\}^{1 / 2},
$$

where $D_{e}$ was the estimated density, $D$ was the true density, and $I=5000$ was the number of replications in the simulation run.

\section{Results AND Discussion}

The results from the 96 simulation runs are summarized as the mean relative root-mean-squared error (RRMSE) for each estimator in each spatial pattern at each sample size (Table 2). We present more condensed results for mean relative bias (RBIAS) in Table 3 . We present our observed statistics from the simulations as "relative" statistics (divided by the true density) to standardize the scale across the density parameter being estimated.

Although there are exceptions, we can make some 
TABle 2. Continued.

\begin{tabular}{|c|c|c|c|c|c|c|c|c|c|c|c|c|c|c|c|}
\hline \multirow[b]{3}{*}{ Estimator } & \multicolumn{15}{|c|}{ Pattern } \\
\hline & \multicolumn{5}{|c|}{ Aggregate-50 } & \multicolumn{5}{|c|}{ Aggregate-15 } & \multicolumn{5}{|c|}{ Double clump } \\
\hline & 5 & 10 & 20 & 50 & Mean & 5 & 10 & 20 & 50 & Mean & 5 & 10 & 20 & 50 & Mean \\
\hline \multicolumn{16}{|l|}{ Basic distance } \\
\hline $\begin{array}{l}\text { 1. BDCI } \\
\text { 2. BDNN } \\
\text { 3. BD2N } \\
\text { 4. BDAV2 } \\
\text { 5. BDAV3 }\end{array}$ & $\begin{array}{l}0.75 \\
0.97 \\
1.15 \\
0.67 \\
0.66\end{array}$ & $\begin{array}{l}0.42 \\
0.52 \\
0.60 \\
0.36 \\
0.35\end{array}$ & $\begin{array}{l}0.29 \\
0.34 \\
0.41 \\
0.22 \\
0.23\end{array}$ & $\begin{array}{l}0.21 \\
0.22 \\
0.29 \\
0.14 \\
0.15\end{array}$ & $\begin{array}{l}0.42 \\
0.51 \\
0.61 \\
0.35 \\
0.35\end{array}$ & $\begin{array}{l}0.74 \\
4.44 \\
7.54 \\
2.20 \\
3.47\end{array}$ & $\begin{array}{l}0.51 \\
2.97 \\
5.64 \\
1.38 \\
2.59\end{array}$ & $\begin{array}{l}0.48 \\
2.57 \\
4.89 \\
1.14 \\
2.27\end{array}$ & $\begin{array}{l}0.48 \\
2.34 \\
4.50 \\
1.00 \\
2.10\end{array}$ & $\begin{array}{l}0.55 \\
3.08 \\
5.64 \\
1.43 \\
2.61\end{array}$ & $\begin{array}{r}0.88 \\
24.44 \\
24.66 \\
12.14 \\
12.81\end{array}$ & $\begin{array}{r}0.66 \\
5.61 \\
13.76 \\
2.60 \\
5.92\end{array}$ & $\begin{array}{r}0.67 \\
4.64 \\
11.70 \\
2.07 \\
5.07\end{array}$ & $\begin{array}{r}0.67 \\
4.17 \\
10.20 \\
1.81 \\
4.64\end{array}$ & $\begin{array}{r}0.72 \\
9.71 \\
15.18 \\
4.66 \\
7.11\end{array}$ \\
\hline \multicolumn{16}{|l|}{ Batcheler-Bell } \\
\hline $\begin{array}{l}\text { 6. BBCI } \\
\text { 7. BBNR }\end{array}$ & $\begin{array}{l}0.76 \\
0.70\end{array}$ & $\begin{array}{l}0.42 \\
0.44\end{array}$ & $\begin{array}{l}0.30 \\
0.30\end{array}$ & $\begin{array}{l}0.24 \\
0.19\end{array}$ & $\begin{array}{l}0.43 \\
0.41\end{array}$ & $\begin{array}{l}0.75 \\
3.30\end{array}$ & $\begin{array}{l}0.54 \\
1.91\end{array}$ & $\begin{array}{l}0.54 \\
1.45\end{array}$ & $\begin{array}{l}0.55 \\
1.19\end{array}$ & $\begin{array}{l}0.59 \\
1.96\end{array}$ & $\begin{array}{r}0.85 \\
52.72\end{array}$ & $\begin{array}{l}0.71 \\
9.36\end{array}$ & $\begin{array}{l}0.72 \\
5.64\end{array}$ & $\begin{array}{l}0.74 \\
3.03\end{array}$ & $\begin{array}{r}0.76 \\
17.89\end{array}$ \\
\hline \multicolumn{16}{|l|}{ Nonparametric } \\
\hline $\begin{array}{l}\text { 8. NPGF } \\
\text { 9. NPIG } \\
\text { 10. NPOF } \\
\text { 11. NPIO }\end{array}$ & $\begin{array}{l}3.12 \\
0.88 \\
5.02 \\
0.93\end{array}$ & $\begin{array}{l}1.14 \\
0.77 \\
0.81 \\
0.55\end{array}$ & $\begin{array}{l}0.80 \\
0.55 \\
0.44 \\
0.41\end{array}$ & $\begin{array}{l}0.45 \\
0.43 \\
0.31 \\
0.30\end{array}$ & $\begin{array}{l}1.39 \\
0.65 \\
1.64 \\
0.55\end{array}$ & $\begin{array}{l}4.02 \\
1.33 \\
6.32 \\
1.52\end{array}$ & $\begin{array}{l}2.35 \\
1.29 \\
1.51 \\
0.77\end{array}$ & $\begin{array}{l}1.63 \\
0.93 \\
0.66 \\
0.59\end{array}$ & $\begin{array}{l}0.77 \\
0.74 \\
0.46 \\
0.43\end{array}$ & $\begin{array}{l}2.20 \\
1.07 \\
2.24 \\
0.83\end{array}$ & $\begin{array}{r}22.23 \\
5.51 \\
34.63 \\
7.42\end{array}$ & $\begin{array}{l}9.15 \\
6.12 \\
9.66 \\
1.63\end{array}$ & $\begin{array}{l}6.05 \\
4.42 \\
1.24 \\
0.99\end{array}$ & $\begin{array}{l}2.05 \\
1.93 \\
0.97 \\
0.86\end{array}$ & $\begin{array}{r}9.87 \\
4.50 \\
11.62 \\
2.73\end{array}$ \\
\hline \multicolumn{16}{|l|}{ Kendall-Moran } \\
\hline $\begin{array}{l}\text { 12. KMP } \\
\text { 13. KM } 2 \mathrm{P}\end{array}$ & $\begin{array}{l}0.44 \\
0.39\end{array}$ & $\begin{array}{l}0.30 \\
0.26\end{array}$ & $\begin{array}{l}0.22 \\
0.19\end{array}$ & $\begin{array}{l}0.17 \\
0.13\end{array}$ & $\begin{array}{l}0.28 \\
0.24\end{array}$ & $\begin{array}{l}0.59 \\
0.67\end{array}$ & $\begin{array}{l}0.39 \\
0.41\end{array}$ & $\begin{array}{l}0.32 \\
0.26\end{array}$ & $\begin{array}{l}0.29 \\
0.17\end{array}$ & $\begin{array}{l}0.40 \\
0.38\end{array}$ & $\begin{array}{l}0.71 \\
0.76\end{array}$ & $\begin{array}{l}0.55 \\
0.44\end{array}$ & $\begin{array}{l}0.53 \\
0.38\end{array}$ & $\begin{array}{l}0.53 \\
0.36\end{array}$ & $\begin{array}{l}0.58 \\
0.49\end{array}$ \\
\hline \multicolumn{16}{|l|}{ T-Square } \\
\hline $\begin{array}{l}\text { 14. TSBA } \\
\text { 15. TSRB } \\
\text { 16. TSB }\end{array}$ & $\begin{array}{l}0.67 \\
0.76 \\
0.73\end{array}$ & $\begin{array}{l}0.40 \\
0.44 \\
0.45\end{array}$ & $\begin{array}{l}0.27 \\
0.29 \\
0.31\end{array}$ & $\begin{array}{l}0.18 \\
0.19 \\
0.21\end{array}$ & $\begin{array}{l}0.38 \\
0.42 \\
0.42\end{array}$ & $\begin{array}{l}0.74 \\
1.16 \\
1.24\end{array}$ & $\begin{array}{l}0.41 \\
0.69 \\
0.78\end{array}$ & $\begin{array}{l}0.30 \\
0.51 \\
0.61\end{array}$ & $\begin{array}{l}0.27 \\
0.40 \\
0.50\end{array}$ & $\begin{array}{l}0.43 \\
0.69 \\
0.78\end{array}$ & $\begin{array}{l}0.75 \\
1.29 \\
1.49\end{array}$ & $\begin{array}{l}0.53 \\
0.69 \\
0.85\end{array}$ & $\begin{array}{l}0.52 \\
0.50 \\
0.64\end{array}$ & $\begin{array}{l}0.52 \\
0.40 \\
0.51\end{array}$ & $\begin{array}{l}0.58 \\
0.72 \\
0.87\end{array}$ \\
\hline \multicolumn{16}{|c|}{ Ordered distance } \\
\hline $\begin{array}{l}\text { 17. ODCI } \\
\text { 18. OD2C } \\
\text { 19. OD3C }\end{array}$ & $\begin{array}{l}0.61 \\
0.42 \\
0.36\end{array}$ & $\begin{array}{l}0.41 \\
0.30 \\
0.25\end{array}$ & $\begin{array}{l}0.31 \\
0.24 \\
0.20\end{array}$ & $\begin{array}{l}0.25 \\
0.19 \\
0.15\end{array}$ & $\begin{array}{l}0.39 \\
0.29 \\
0.24\end{array}$ & $\begin{array}{l}0.67 \\
0.52 \\
0.45\end{array}$ & $\begin{array}{l}0.60 \\
0.45 \\
0.35\end{array}$ & $\begin{array}{l}0.59 \\
0.43 \\
0.32\end{array}$ & $\begin{array}{l}0.59 \\
0.43 \\
0.30\end{array}$ & $\begin{array}{l}0.61 \\
0.46 \\
0.36\end{array}$ & $\begin{array}{l}0.78 \\
0.65 \\
0.56\end{array}$ & $\begin{array}{l}0.76 \\
0.63 \\
0.52\end{array}$ & $\begin{array}{l}0.77 \\
0.64 \\
0.52\end{array}$ & $\begin{array}{l}0.77 \\
0.64 \\
0.53\end{array}$ & $\begin{array}{l}0.77 \\
0.64 \\
0.53\end{array}$ \\
\hline \multicolumn{16}{|l|}{ Angle-Order } \\
\hline $\begin{array}{l}\text { 20. } \mathrm{AO} 1 \mathrm{Q} \\
\text { 21. } \mathrm{AO} 2 \mathrm{Q} \\
\text { 22. } \mathrm{AO} 3 \mathrm{Q} \\
\text { 23. } \mathrm{AO} 3\end{array}$ & $\begin{array}{l}0.45 \\
0.31 \\
0.25 \\
0.37\end{array}$ & $\begin{array}{l}0.34 \\
0.22 \\
0.18 \\
0.28\end{array}$ & $\begin{array}{l}0.24 \\
0.16 \\
0.13 \\
0.22\end{array}$ & $\begin{array}{l}0.16 \\
0.11 \\
0.10 \\
0.17\end{array}$ & $\begin{array}{l}0.30 \\
0.20 \\
0.17 \\
0.26\end{array}$ & $\begin{array}{l}0.78 \\
0.43 \\
0.32 \\
0.77\end{array}$ & $\begin{array}{l}0.59 \\
0.33 \\
0.24 \\
0.60\end{array}$ & $\begin{array}{l}0.44 \\
0.28 \\
0.19 \\
0.52\end{array}$ & $\begin{array}{l}0.33 \\
0.23 \\
0.15 \\
0.45\end{array}$ & $\begin{array}{l}0.54 \\
0.31 \\
0.22 \\
0.58\end{array}$ & $\begin{array}{l}1.36 \\
0.67 \\
0.50 \\
1.45\end{array}$ & $\begin{array}{l}1.07 \\
0.55 \\
0.41 \\
1.13\end{array}$ & $\begin{array}{l}0.78 \\
0.48 \\
0.35 \\
0.91\end{array}$ & $\begin{array}{l}0.54 \\
0.40 \\
0.31 \\
0.76\end{array}$ & $\begin{array}{l}0.94 \\
0.52 \\
0.39 \\
1.07\end{array}$ \\
\hline 24. VAT & 0.34 & 0.24 & 0.17 & 0.13 & 0.22 & 0.44 & 0.33 & 0.29 & 0.27 & 0.33 & 0.53 & 0.46 & 0.45 & 0.45 & 0.47 \\
\hline 25. QUAD & 0.28 & 0.20 & 0.14 & 0.10 & 0.18 & 0.37 & 0.26 & 0.19 & 0.12 & 0.23 & 0.50 & 0.35 & 0.25 & 0.16 & 0.31 \\
\hline
\end{tabular}

general observations about the results before looking at specific areas of interest. None of these general observations are unexpected. From Tables 2 and 3 we see that the quality of estimation generally decreased as the populations deviated further from a random pattern, especially when there was severe clumping. The triangular pattern posed a greater problem for some estimators (BDCI, BBCI, KM2P, ODCI) than a high degree of aggregation. The random, regular, and even the moderately clumped aggregate- 50 pattern each allowed most estimators to have their best performances. The least surprising result was that performance improved as sample sizes increased. The sample size varied among the estimators at which RRMSE improvement began to diminish and depended on the spatial pattern of the sampled population. For the better-performing estimators discussed in Conclusions, sample sizes involving 20 to $<50$ (say 30 ) random points appeared to be adequate for most situations. RRMSEs tended to improve as densities increased, especially for patterns with aggregation. The quadrat estimator out- performed the others overall, although with the variety of estimators and simulation situations, a comparison of effort involved is difficult to assess. That the RBIAS results for the quadrat estimator were all near zero provided reassurance on the theoretical quality of the simulations. In the subsections that follow we will see that the best-performing estimators overall require locating $>1$ population individual per sample point.

We calculated a four-factor factorial ANOVA on the RRMSE and RBIAS results to help define the factors influencing estimation quality (Table 4). The largest share of the variation in the RRMSE results was produced by the four main effects of estimator, pattern, sample size, and density, plus the sample size $\times$ pattern and the pattern $\times$ density interactions. The main effects, except for sample size, and the estimator $\times$ pattern and pattern $\times$ density interactions accounted for the greatest amount of variation in the RBIAS results. The investigator cannot control pattern or density in the field, and the effect of sample size is straightforward. Therefore, we concentrate our attention on es- 
TABLE 3. Mean relative bias (RBIAS) for each estimator in each spatial pattern. Estimator notation defined in Table 1.

\begin{tabular}{|c|c|c|c|c|c|c|}
\hline Estimator & Random & Regular & Triang. & Aggt. 50 & Aggt. 15 & Double \\
\hline $\begin{array}{l}\text { 1. BCDI } \\
\text { 2. BDNN } \\
\text { 3. BD2N } \\
\text { 4. BDAV2 } \\
\text { 5. BDAV3 }\end{array}$ & $\begin{array}{l}0.10 \\
0.14 \\
0.04 \\
0.12 \\
0.09\end{array}$ & $\begin{array}{r}0.37 \\
-0.11 \\
-0.30 \\
0.13 \\
-0.02\end{array}$ & $\begin{array}{r}0.65 \\
-0.66 \\
-0.68 \\
-0.01 \\
-0.23\end{array}$ & $\begin{array}{r}-0.04 \\
0.18 \\
0.22 \\
0.07 \\
0.12\end{array}$ & $\begin{array}{r}-0.39 \\
2.49 \\
4.84 \\
1.05 \\
2.32\end{array}$ & $\begin{array}{r}-0.61 \\
4.60 \\
11.75 \\
1.99 \\
5.24\end{array}$ \\
\hline $\begin{array}{l}\text { 6. } \mathrm{BBCI} \\
\text { 7. } \mathrm{BBNR}\end{array}$ & $\begin{array}{l}0.12 \\
0.02\end{array}$ & $\begin{array}{l}0.45 \\
0.04\end{array}$ & $\begin{array}{l}0.76 \\
0.07\end{array}$ & $\begin{array}{r}-0.07 \\
0.04\end{array}$ & $\begin{array}{r}-0.46 \\
1.06\end{array}$ & $\begin{array}{r}-0.68 \\
4.23\end{array}$ \\
\hline $\begin{array}{l}\text { 8. NPGF } \\
\text { 9. NPIG } \\
\text { 10. NPOF } \\
\text { 11. NPIO }\end{array}$ & $\begin{array}{r}0.04 \\
-0.13 \\
0.16 \\
-0.18\end{array}$ & $\begin{array}{r}0.07 \\
-0.09 \\
0.22 \\
-0.10\end{array}$ & $\begin{array}{r}0.12 \\
-0.04 \\
0.31 \\
-0.01\end{array}$ & $\begin{array}{r}0.06 \\
-0.13 \\
0.16 \\
-0.19\end{array}$ & $\begin{array}{r}0.28 \\
-0.03 \\
0.23 \\
-0.26\end{array}$ & $\begin{array}{r}1.22 \\
0.42 \\
0.88 \\
-0.16\end{array}$ \\
\hline $\begin{array}{l}\text { 12. } \mathrm{KMP} \\
\text { 13. } \mathrm{KM} 2 \mathrm{P}\end{array}$ & $\begin{array}{l}0.03 \\
0.04\end{array}$ & $\begin{array}{r}0.06 \\
-0.03\end{array}$ & $\begin{array}{l}-0.45 \\
-0.49\end{array}$ & $\begin{array}{l}-0.08 \\
-0.02\end{array}$ & $\begin{array}{r}-0.21 \\
0.04\end{array}$ & $\begin{array}{l}-0.48 \\
-0.27\end{array}$ \\
\hline $\begin{array}{l}\text { 14. TSBA } \\
\text { 15. TSRB } \\
\text { 16. TSB }\end{array}$ & $\begin{array}{l}0.28 \\
0.32 \\
0.28\end{array}$ & $\begin{array}{l}0.39 \\
0.40 \\
0.26\end{array}$ & $\begin{array}{l}-0.16 \\
-0.02 \\
-0.16\end{array}$ & $\begin{array}{l}0.13 \\
0.20 \\
0.21\end{array}$ & $\begin{array}{r}-0.13 \\
0.44 \\
0.52\end{array}$ & $\begin{array}{r}-0.44 \\
0.32 \\
0.50\end{array}$ \\
\hline $\begin{array}{l}\text { 17. ODCI } \\
\text { 18. OD2C } \\
\text { 19. OD3C }\end{array}$ & $\begin{array}{l}0.02 \\
0.02 \\
0.02\end{array}$ & $\begin{array}{l}0.38 \\
0.20 \\
0.13\end{array}$ & $\begin{array}{l}0.90 \\
0.16 \\
0.29\end{array}$ & $\begin{array}{l}-0.15 \\
-0.12 \\
-0.09\end{array}$ & $\begin{array}{l}-0.56 \\
-0.38 \\
-0.25\end{array}$ & $\begin{array}{l}-0.75 \\
-0.61 \\
-0.48\end{array}$ \\
\hline $\begin{array}{l}\text { 20. } \mathrm{AO} 1 \mathrm{Q} \\
\text { 21. } \mathrm{AO} 2 \mathrm{Q} \\
\text { 22. } \mathrm{AO} 3 \mathrm{Q} \\
\text { 23. } \mathrm{AO} 3\end{array}$ & $\begin{array}{l}0.01 \\
0.02 \\
0.02 \\
0.01\end{array}$ & $\begin{array}{r}0.17 \\
0.09 \\
0.07 \\
-0.11\end{array}$ & $\begin{array}{r}0.47 \\
0.09 \\
0.13 \\
-0.10\end{array}$ & $\begin{array}{l}0.06 \\
0.04 \\
0.04 \\
0.12\end{array}$ & $\begin{array}{r}-0.22 \\
-0.19 \\
-0.11 \\
0.39\end{array}$ & $\begin{array}{r}-0.29 \\
-0.35 \\
-0.27 \\
0.63\end{array}$ \\
\hline 24. VAT & 0.02 & 0.13 & 0.31 & -0.06 & -0.21 & -0.41 \\
\hline 25. QUAD & $0.00^{*}$ & -0.01 & 0.02 & 0.03 & 0.01 & 0.02 \\
\hline
\end{tabular}

* Absolute value of RBIAS $<0.01$.

timator performance overall and within spatial patterns.

\section{"Basic" distance estimators}

It is well known that these estimators do not perform well when the spatial pattern deviates substantially from random (e.g., Cottam et al. 1957, Persson 1971, Pollard 1971, Clayton and Cox 1986). The results in the tables indicate that the BDCI estimator performed most poorly when applied to populations with a triangular pattern, which is not surprising because the closest individual measurement would give less adequate information about the distance between population individuals than

TABLE 4. Analysis of variance on relative root-mean-squared error (RRMSE) and relative bias (RBIAS) results for the 96 simulations.

\begin{tabular}{|c|c|c|c|}
\hline Source & df & $\begin{array}{l}\text { RRMSE } \\
\text { MSE }\end{array}$ & $\begin{array}{c}\text { RBIAS } \\
\text { MSE }\end{array}$ \\
\hline Estimator (E) & 24 & 125.7 & 37.5 \\
\hline Pattern (P) & 5 & 710.8 & 62.8 \\
\hline Sample Size (S) & 3 & 333.2 & 5.3 \\
\hline Density (D) & 3 & 488.2 & 76.9 \\
\hline $\mathrm{E} \times \mathrm{P}$ & 120 & 65.6 & 22.9 \\
\hline$E \times S$ & 72 & 35.2 & 0.6 \\
\hline$E \times D$ & 72 & 49.4 & 11.7 \\
\hline $\mathbf{P} \times \mathbf{S}$ & 15 & 141.8 & 1.1 \\
\hline$P \times D$ & 15 & 303.0 & 37.4 \\
\hline$S \times D$ & 9 & 91.3 & 0.7 \\
\hline$E \times P \times S$ & 360 & 20.9 & 0.2 \\
\hline$E \times P \times D$ & 360 & 35.3 & 5.5 \\
\hline$E \times S \times D$ & 216 & 16.4 & 0.1 \\
\hline$P \times S \times D$ & 45 & 72.5 & 0.4 \\
\hline$E \times P \times S \times D$ & 1080 & 14.5 & 0.1 \\
\hline
\end{tabular}

the nearest neighbor $(\mathrm{NN})$ or the second nearest neighbor $(2 \mathrm{~N})$. The BDNN and BD2N, and therefore, the BDAV2 and BDAV 3 estimators each performed poorly at the more highly aggregated patterns, aggregate-15 and double clumped. Entering this study we were hopeful that estimators based on means of the BDCI and BDNN (and BD2N) estimators would perform well in aggregated populations by smoothing the effects of measuring distances to an individual in a clump as contrasted with measuring the distances between individuals within a clump. However, the estimators in this group that use the $\mathrm{NN}$ and/or $2 \mathrm{~N}$ measurements had among the worst performance properties of all estimators studied. The BDCI estimator performed the best of the estimators in this group for very clumped patterns and was similar to such other estimators as BBCI and ODCI, which also are based only on the measurement to the closest individual.

\section{"Batcheler-Bell" estimators}

$\mathrm{BBCI}$ is an estimator based on the area searched for the closest individual (CI), whereas the other estimator in this section, BBNR, uses the search areas to the nearest neighbor and second nearest neighbor to correct for bias arising from nonrandomness in the population spatial pattern. The simulations resulted in the BBNR estimator usually having lower RRMSE and RBIAS than BBCI in each of the patterns without a high degree of aggregation. However, for the aggregate15 and the double-clumped populations BBCI was superior to BBNR, as BBNR was probably the poorest 
performing estimator of all for these patterns. The differences in quality of estimation were most pronounced for the smaller sample sizes. Neither of these estimators were among the better-performing estimators.

\section{Nonparametric estimators}

The most pronounced result among the four nonparametric estimators was that the RRMSE performance for the interpolated forms was consistently and substantially superior (lower RRMSE) than for the uninterpolated forms. However, interpolation did not consistently produce superior RBIAS results. As would be expected when selecting a single-order statistic for estimation in the uninterpolated forms, the beneficial effect from interpolation decreased as sample size increased. The interpolated and uninterpolated forms gave similar estimation results once sample sizes reached 50.

Patil et al. (1982) revised their estimator to the NPOF form to reduce bias and improve precision. Therefore, we wanted to compare the performance of this estimator to their original recommendation where the exponent in the sequence used to define the ordered search area in the estimate was $1 / 2$ (not 2/3). However, we used the bias-reduced form to calculate NPGF so that NPGF and NPOF are of comparable forms. The NPGF estimator invariably resulted in lower RRMSEs than NPOF at the sample size of 5 random points, whereas NPOF had lower RRMSEs at all other sample sizes $(10,15,20$, and 50 random points). When interpolation was added to the estimation method, the NPIO was superior to the NPIG in almost every simulation.

NPGF and NPOF usually were among the estimators with highest RRMSEs. The interpolated versions had performances in the mid-range of the estimators studied and they were relatively consistent across spatial patterns.

\section{"Kendall-Moran" estimators}

Both the KMP and KM2P estimators performed better than most of the other estimators, especially in the presence of aggregation. Only the triangular pattern posed difficulties for these estimators, as they were in the mid-range among estimators for that pattern. The great majority of the simulations resulted in the KM2P estimator having a smaller RRMSE than KMP. Inclusion of the search area to the second nearest neighbor consistently improved estimation. Overall, KM2P was among the 3-4 best-performing estimators and KMP was in the top 7-8 ones.

\section{$T$-square estimators}

The performances of the three $\mathrm{T}$-square estimators were generally similar; however, the usual $\mathrm{T}$-square estimator, TSBA, performed slightly better than the other two in four of the six spatial patterns. All three performed best in the triangular spatial pattern. In contrast to what was hypothesized by Diggle (1975), the
TSRB estimator did not improve RRMSE performance over TSBA in the aggregate patterns, nor did it decrease RBIAS in most aggregated situations. TSB also did not have as low RRMSEs as TSBA in most cases, nor did it show a reduction in RBIAS. In general these estimators were in the mid-range of performances among all of the PDEs tested.

\section{Ordered distance estimators}

Except for the triangular spatial pattern, the performances among these estimators improved as $g$, the number of individuals located at each random point, increased to 3. Use of $g=2$ was superior for the triangular pattern. We do not know at what value of $g$ one might see diminishing returns, but in terms of practicality in the field one probably would not want to increase $g$ much beyond 3, if at all. OD3C was one of the better performing PDEs, similar to KM2P; OD2C also performed reasonably well, at a level near to KMP.

\section{Angle-order estimators}

The quality of estimation improved as $g$ increased from 1 to 3 in AO1Q, AO2Q, and AO3Q, except for the triangular pattern where $g=2$ was superior, as with the ordered distance estimators. AO1Q was in the midrange RRMSE performance of all PDEs, AO2Q was one of the best ones (especially for the triangular pattern), as was AO3Q, which was probably the best performing PDE overall. AO3, which is of a different form than for $A O 1 Q, A O 2 Q, A O 3 Q$, performed well for the random and uniform patterns (but generally not as well as $\mathrm{AO}$ Q, which also locates three individuals per quadrant) and it was one of the best PDEs for the triangular pattern. This form, however, did not perform as well in aggregated patterns, especially the double-clumped populations. $\mathrm{AO} 3$ generally resulted in an RBIAS with the opposite sign from the other three estimators in this group. Each of the angle-order estimators requires keeping track of four quadrants around the random point and locating a total of $4,8,12$, and 12 population individuals at each random point for AO1Q, AO2Q, AO3Q, and AO3, respectively. This represents considerable effort in difficult field situations and is contrary to the reason for favoring PDEs over quadrats.

\section{Variable area transect}

In most situations VAT was one of the best-performing methods overall, comparable to KM2P and OD3C. Considering that the field worker needs only to search in one direction at each random point, it is probably the easiest method of sampling among the PDEs that require locating $>1$ population individual.

\section{CONCLUSIONS}

There are a considerable number of sampling methods to ponder when devising a sampling scheme for a field study. In the previous section we examined some 
questions of interest concerning the performance of the estimators included in this study. In the process we gained insight as to which are the best performing in a variety of circumstances.

We conclude this paper by giving our opinions, based on the study results presented here, as to what plotless density estimators (PDEs) (see Table 1) we would consider when designing a field study. We assume that an investigator would have an idea as to how much effort and/or cost is involved in making observations in the field. We also assume that, if a PDE is to be used as the primary measurement, then quadrat sampling is inappropriately difficult or expensive for the particular field situation. For our general recommendations, we do not assume that the investigator would be able to clearly define what sort of spatial pattern is followed by the population to be sampled.

Based on the simulation results, our opinion as to the ranking of the "best performing" PDEs would be $\mathrm{AO} 3 \mathrm{Q}$, then $\mathrm{AO} 2 \mathrm{Q}$, followed by the group comprised of $\mathrm{KM} 2 \mathrm{P}$, OD3C, and VAT. The next group would include KMP and OD2C. When assessing an estimator's performance, we prefer to emphasize how well it performs in nonrandom patterns, especially aggregated patterns, because our experience has been that random patterns are rarely, if ever, encountered. The RRMSE results from the three types of spatial patterns that involve aggregation further distinguish the estimators listed above as superior to the others. In terms of RBIAS (mean relative bias) for aggregated populations, KM2P was the best, followed by AO3Q, with no particular pattern among the rest of the top estimators.

Concerning the angle-order methods, we agree with Pollard's (1971) comment on the point-centered-quarter method that estimation advantages are out-weighed by the practical difficulties of dividing the plane around the sampling point into quadrants, deciding into which quadrant an individual belongs as part of the process for determining and measuring the $g$ closest individuals in that quadrant. (We could make a similar comment about the use of T-square estimators, but we are not considering them in this discussion because their simulation performances were not as good as for those listed above.) Even if determination of quadrants were not a problem, angle-order estimators generally require locating more individuals at each sample point than the other PDEs studied (where $\leq 3$ individuals are located). The added effort does not seem to be rewarded with enough improvement in quality of estimation to warrant its use in most circumstances. In naturally occurring populations, spatial patterns and object density usually are not as consistent over an area as our computer simulated populations. Hence, we feel that for fixed effort in the field, it usually is more useful to sample more spatial points and have less effort per point. This argues against methods such as angle-order where the effort would be intensively applied at fewer random points.
Using the above arguments and rankings of results, we consider the KM2P, OD3C, and VAT to be the three most practical PDEs. For our simulations, each of these methods involved locating three population individuals per random sample point. The next group would include KMP and OD2C, which involve locating two population individuals per point. The availability of reliable software could influence an investigator's decision as to which method to apply in the field. The algorithm for calculating the KM2P estimate is not trivial. The algorithm for KMP is an order of magnitude less difficult than for KM2P, but it is still considerably more complicated than those for OD3C, VAT, and OD2C, which are simple. The VAT estimate is easily calculated by hand. To make software availability less of a consideration for selection of an estimation method, we are currently developing our simulation algorithms into a user-friendly package capable of calculating each of the estimators considered in this study. This package also will include available variance estimates for each method, whether they are exact, asymptotic or approximate, or based on a resampling method. We are planning another simulation study to address the quality of variance estimation for the better-performing estimators from this study.

We evaluated the estimators considered for this study using extensive simulations of a variety of population patterns. However, in most natural areas the pattern and/or density of the population being sampled can vary greatly. Therefore, the true test of the estimators would be which ones perform well in field situations. We are currently developing data sets, where the locations of each individual in a variety of natural populations are recorded. These large data sets, which are quite varied in pattern and density, will be used in a follow-up study to compare estimator performance from naturally occurring, but totally delineated, populations with known densities.

\section{ACKNOWLEDGMENTS}

We would like to thank Ken Burnham and Dave Otis for their helpful reviews and comments prior to submission of this work. The School of Life Sciences of the Queensland University of Technology, Brisbane, Australia, provided generous logistical and computing support, without which this work would not yet be complete. Mark Otto, Gary White, and Philip Dixon provided the most comprehensive and beneficial manuscript reviews that we have experienced.

\section{LITERATURE Cited}

Batcheler, C. L. 1971. Estimation of density from a sample of joint point and nearest neighbour distances. Ecology 53: 703-709.

. 1975. Development of a deer census from pellet groups. Journal of Wildlife Management 39:641-652.

Batcheler, C. L., and D. J. Bell. 1970. Experiments in estimating density from joint point and nearest neighbour distances. Proceedings of the New Zealand Ecological Society 17:111-117.

Besag, J. E., and J. T. Gleaves. 1973. On the detection of spatial pattern in plant communities. Bulletin of the International Statistical Institute 45:153-158. 
Bratley, P., B. L. Fox, and L. E. Schrage. 1983. A guide to simulation. Springer-Verlag, New York, New York, USA.

Brody, M., and D. Morais. 1987. UNIF is fast, reliable random number generator for IBM-AT microcomputer. Research Information Bulletin number 87-84. USDI Fish and Wildlife Service, Washington, D.C., USA.

Buckland, S. T. 1987. On the variable circular plot method of estimating animal density. Biometrics 43:363-384.

Burnham, K. P., D. R. Anderson, J. L. Laake. 1980. Estimation of density from line transect sampling of biological populations. Wildlife Monographs 72:1-202.

Byth, K. 1982. On robust distance-based intensity estimators. Biometrics 38:127-135.

Clayton, G., and T. F. Cox. 1986. Some robust density estimators for spatial point processes. Biometrics 42:753767.

Cottam, G. 1947. A point method for making rapid surveys of woodlands. Bulletin of the Ecological Society of America 28:60.

Cottam, G., and J. T. Curtis. 1956. The use of distance measures in phytosociological sampling. Ecology 37:451460.

Cottam, G., J. T. Curtis, and A. J. Catana. 1957. Some sampling characteristics of a series of aggregated populations. Ecology 38:610-621.

Cottam, G., J. T. Curtis, and B. W. Hale. 1953. Some sampling characteristics of a population of randomly dispersed individuals. Ecology 34:741-757.

Delince, J. 1986. Robust density estimation through distance measurements. Ecology 67:1576-1581.

Diggle, P. J. 1975. Robust density estimation using distance methods. Biometrika 62:39-48.

Engeman, R. M., and J. F. Bromaghin. 1990. An approach to estimating density from line transect data where animals move in response to the observer. Journal of Statistical Computation and Simulation 34:145-154.
James, I. L. 1971. A computer study of corrected density estimators for distance sampling of nonrandom populations. Diploma of Agricultural Science, Dissertation. Massey University, Palmerston North, New Zealand.

Kendall, M. G., and P. A. P. Moran. 1963. Geometrical probability. Griffin, London, England.

Lewis, S. M. 1975. Robust estimation of density for a twodimensional point process. Biometrika 62:519-521.

Morisita, M. 1954. Estimation of population density by spacing method. Memoirs of the Faculty of Science Kyushu University, Series E, Biology 1:187-197.

- 1957. A new method for the estimation of density by spacing method applicable to nonrandomly distributed populations. Physiology and Ecology 7:134-144 (in Japanese). [Available as Forest Service translation number 11116, USDA Forest Service, Washington, D.C., USA.]

Parker, K. R. 1979. Density estimation by variable area transect. Journal of Wildlife Management 43:484-492.

Patil, S. A., K. P. Burnham, and J. L. Kovner. 1979. Nonparametric estimation of plant density by the distance method. Biometrics 35:597-604.

Patil, S. A., J. L. Kovner, and K. P. Burnham. 1982. Optimum nonparametric estimation of population density based on ordered distances. Biometrics 38:243-248.

Persson, O. 1971. The robustness of estimating density by distance measurements. Pages 175-187 in G. P. Patil, E. C. Pielou, and W. E. Waters, editors. Statistical ecology. Volume 2. Pennsylvania State University Press, University Park, Pennsylvania, USA.

Pollard, J. H. 1971. On distance estimators of density in randomly distributed forests. Biometrics 27:991-1002.

Stearns, F. W. 1949. Ninety years change in a northern hardwood forest in Wisconsin. Ecology 30:350-358. 